\title{
BOT FLY TYPES IN THE MUSEUM OF COMPARATIVE ZOOLOGY (DIPTERA: OESTRIDAE)
}

\author{
NORMAN E. WOODLEY \\ Systematic Entomology Laboratory, PSI, ARS, USDA \\ c/o National Museum of Natural History NHB 168 \\ Washington, D.C. 20560
}

\begin{abstract}
The primary types of 5 bot fly taxa in the entomology collection of the Museum of Comparative Zoology are listed and discussed. Syntypes of Gasterophilus pecorum var. zebrae Rodhain and Bequaert and Kirkia minuta Rodhain and Bequaert, previously believed to be lost, are present in the collection. Specimens of two taxa labeled as types have no type status.
\end{abstract}

\section{INTRODUCTION}

While the number of bot fly types in the Museum of Comparative Zoology, Harvard University, Cambridge, Massachusetts, U.S.A., is few, it is important to document them, as some have been reported as lost in the literature. Primary type material of five taxa is present in the entomological collection of the MCZ.

The exact label data are presented for each type specimen, and remarks are made concerning the status of each. For four of the taxa, the types discussed are syntypes. It is not desirable to designate lectotypes at this time, because the taxonomic history of some of these taxa is complicated, and both larvae and adults were described concurrently in several cases. Thus, syntypes from two life stages were present, and subsequent bot-fly workers have pointed out that in some cases the larvae and adults were apparently not conspecific. Lectotype designations should be made only after thorough study of all available material for each taxon.

Specimens belonging to two taxa with type notations on their labels were found to have no type status and are discussed after the type list. There is other oestrid material of interest in the MCZ

Manuscript received 6 June 1994. 
collection, especially that originating from Africa from the Bequaert collection. Bequaert was associated with Harvard University for many years (Carpenter, 1982), and his extensive collection of medical and veterinary Diptera is now at the MCZ. For instance, the specimens of Pharyngobolus africanus Brauer, reared by Rodhain and Bequaert from African elephants and stated as being lost by Zumpt and Wetzel (1970: 109), are present in the collection.

\section{Primary Types}

chrysidiformis Rodhain \& Bequaert, 1915c: 773. [Cobboldia].

Current valid name: Cobboldia chrysidiformis Rodhain \& Bequaert.

Syntypes: 4 ơ, 3 o. All specimens are labeled in nearly identical fashion in Bequaert's handwriting: "Ouellé Rodhain/ex Elaphus africanus/Cobboldia chrysidiformis Rodh et Beq." One specimen has an additional notation at the bottom of the third label: "o type." One of the other specimens lacks the third label entirely. I have added to each specimen the following label: "SYNTYPE o" [or o] MCZ \#32556 Cobboldia chrysidiformis Rodhain \& Bequaert 1915 teste Woodley 1980."

As Bequaert labeled one of these specimens as "type", and the specimens are from the type locality, it seems almost certain that they are original syntypes. The original description does not specify the number of specimens examined but implies there was a good series present. Larvae and puparia were also described concurrently and are technically also syntypes as no formal type designation was made, although the adult description was printed in a different type face implying that it was the "official" description. The larvae, according to Zumpt and Wetzel (1970), are a taxon distinct from the adults and referable to Cobboldia roverei Gedoelst.

Other adult specimens with similar label data are present in the MCZ, but the labels are of a different style. It seems likely that they were collected subsequent to the original description.

Zumpt and Wetzel (1970) discussed the confusion in the taxonomy of this species, but did not mention examination of any type material. It is possible that there are additional syntypes in European museums. Cobboldia chrysidiformis is currently regarded as a valid taxon and has no synonyms. 
minuta Rodhain \& Bequaert, 1915a: 456. [Kirkia].

Current valid name: Kirkioestrus minutus (Rodhain \& Bequaert).

Syntype: 1 o. The specimen is labeled: "Ouelle Rodhain/ex Bubalis lelwel jacksoni/Kirkioestrus minutus Rodh. et Beq. o type/SYNTYPE MCZ \#32566 Kirkia minuta Rodhain \& Bequaert 1915: 456 teste Woodley 1981."

As larvae were described concurrently with the adult female, with no formal type designation, this specimen (apparently the only adult seen by Rodhain and Bequaert) must be considered a syntype. Zumpt (1962: 398) mentioned that the "adult specimen could not later be found in any of the Belgian institutes." However, he was able to examine the original larval material at Tervuren.

Rodhain and Bequaert (1915b) later proposed the replacement name Kirkioestrus for Kirkia Gedoelst, 1914, preoccupied by Kirkia Pollonera (1909, Mollusca).

paradoxa Rodhain \& Bequaert, 1915a: 453. [Gedoelstia].

Current valid name: Gedoelstia haessleri Gedoelst, but see discussion below.

Syntypes: 4 ơ, 2 ९. All six specimens have labels reading: "Ouellé Rodhain/ex Bubalis lelwel jacksoni." Three males and one female have an additional label reading "Oestrus variolosus Lw." The remaining male bears a label which reads: "Oestrus variolosus Lw (=Ged. paradoxa o R \& B)." The other female bears a label reading: "Gedoelstia paradoxa $R \& B$ type $=$ Oe. variolosus Lw." I have added a label to each of the six specimens which reads: "SYNTYPE MCZ \# 32567 Gedoelstia paradoxa Rodhain \& Bequaert 1915: 453 teste Woodley 1981."

The locality and host data of these specimens, and the labels written by Bequaert, indicate that the material at hand is from the original type series. Adults and larvae were described concurrently and should be regarded as syntypes. Rodhain and Bequaert (1916: 143) and Emden (1945: 424-425) suggested that the adults described by Rodhain and Bequaert are conspecific with Oestrus variolosus Loew, while the larvae are conspecific with Gedoelstia haessleri Gedoelst. Pont (1980) lists only the latter synonymy. The adult syntypes in the MCZ key to Oestrus variolosus [as Loewioestrus variolosus] in Papavero's (1977) key. The correct 
synonymy can only be established by designating either an adult or larva as lectotype.

scutellaris Brauer, 1863: 230. [Cuterebra].

Current valid name: Cuterebra emasculator Fitch.

Holotype o. The specimen bears the following labels: "Loew Coll./scutellar [rest apparently cut off]/emasculato [sic] Fitch./ Cuterebra emasculator Fitch Det. Dalmat/M.C.Z. Type 29290/ HOLOTYPE Cuterebra scutellaris Loew, in Brauer, 1863: 230. see letter of 29 March 1954, in Sabrosky file. labeled 1981 NEW."

A letter dated 29 March 1954, from Curtis W. Sabrosky to J. Bequaert (presently in the Sabrosky file of correspondence in the entomology department, MCZ), states: "I have now heard from both Dr. Peus at Berlin and Dr. Helmut Mayer, and there are no specimens of Cuterebra scutellaris in either the Loew collection or in Brauer's. Nor any material of it under the name emasculator. It seems perfectly certain, therefore, that the specimen in the MCZ is actually the holotype of $C$. scutellaris, and I believe it should be so labeled."

This name is currently considered a synonym of Cuterebra emasculator Fitch. While Brauer (1863) clearly attributed this name to Loew, he apparently published Loew's manuscript name with his own description (Sabrosky, 1986), and thus is the author of the name.

zebrae Rodhain \& Bequaert, 1920: 181. [as variety of Gasterophilus pecorum].

Current valid name: Gasterophilus pecorum (Fabricius).

Syntypes: 10 , 1 o. The male is labeled: "Namirembe East Africa from Zebra." The female is labeled: "Namirembe East Africa from Equus böhmi/Gasterophilus pecorum var. zebrae R.\& B. type." I have added a label to each specimen which reads: "SYNTYPE ơ [or ९] MCZ \# 32557 Gasterophilus pecorum var. zebrae Rodhain \& Bequaert 1920: 181 teste Woodley 1981."

This taxon was originally described from larvae and one pair of adults, with no formal type designation. Zumpt (1958: 60-64) discussed the taxonomy of this taxon and came to the conclusion that the larvae and adults described by Rodhain and Bequaert were not conspecific. Zumpt (1958: 64) did not examine the adult types as 
he could not find them in Rodhain's collection in Belgium, and regarded them as lost.

The two specimens in the MCZ are undoubtedly the two adults seen by Rodhain and Bequaert. They are labeled in Bequaert's handwriting and are from the stated type locality. In addition, both specimens are in poor condition, which was noted in the original description. The female specimen is missing the right wing, apparently being the wing that Rodhain and Bequaert (1920: 187) mounted on a slide. The slide is evidently lost.

Gasterophilus pecorum var. zebrae is considered a synonym of G. pecorum (Fabricius).

Specimens labeled as, but not Primary Types

magnicornis Bezzi, 1916: 29. [Gasterophilus].

Current valid name: Gasterophilus intestinalis (De Geer).

Specimens: 1 @ labeled: "Ghinda Eritrea/Gasterophilus magnicornis \& Bezzi cotype/Gasterophilus magnicornis ? cotype Bezzi/PROBABLY NOT A TYPE teste Woodley 1980".

As Bezzi (1916) implied designation of a single type (of six specimens examined) by stating "typus in collectione auctoris", the MCZ specimen is at best a paratype even though the third label is apparently in Bezzi's handwriting. In addition, the type material was said to be from "Erythraea, Chenofenà", not Ghinda. Although this specimen was examined by Bezzi, the question mark on his label indicates his doubt as to its identity, and he did not cite it in his publication. Gasterophilus magnicornis is now considered a junior synonym of G. intestinalis (De Geer).

surcoufi Gedoelst, 1914: 212 [1915: 144]. [Kirkia].

Current valid name: Kirkioestrus blanchardi Gedoelst.

Specimens: $10^{\circ}, 1$ o, both labeled: "ex Bubalis lelwel jacksoni/Ouellé Rodhain/Kirkioestrus surcoufi Ged type $\odot$ [or cotype o]/NOT A TYPE teste Woodley 1980."

In his original papers Gedoelst described only larvae, none of which was collected at Ouellé by Rodhain. Thus, these specimens have no type status even though labeled as such by Bequaert. These specimens were probably among those examined and described by Rodhain and Bequaert (1915a) as "Kirkia sp. (? blanchardi Ged.)", later found to belong to K. surcoufi (Rodhain 
and Bequaert, 1915b: 694). The label data conform to those published by them. Bequaert probably labeled the specimens as types because they were the first adult flies to be described. Zumpt (1962) was not able to find Gedoelst's original type material in Belgium.

The current combination for this name is Kirkioestrus surcoufi (Gedoelst), and it is considered a junior synonym of Kirkioestrus blanchardi (Gedoelst).

\section{ACKNOWLEDGEMENTS}

I thank Wayne N. Mathis and Gregory W. Courtney of the Smithsonian Institution, and David R. Smith and Allen L. Norrbom of the Systematic Entomology Laboratory, for reviewing the manuscript.

\section{Literature Cited}

Bezzi, M. 1916. Una nuova specie di Estride dell'Eritrea. Bollettino del Laboratorio di Zoologia generale e agraria della R. Scuola superiore d'Agricoltura in Portici, 10: 27-32.

Brauer, F. 1863. Monographie der Oestriden. Carl Ueberreuter, Wien. vi + 292 pp., 10 pls.

Carpenter, F. M. 1982. Joseph Charles Bequaert. Psyche, 89: 1-2.

Emden, F. van. 1945. Keys to Ethiopian Tachinidae.-I. Phasiinae. Proceedings of the Zoological Society of London, 114: 389-436. (1944).

Gedoelst, L. 1914. Note sur un genre nouveau d'Oestride. Bulletin de la Société de Pathologie Exotique, 7: 210-212.

- 1915. Notes sur les Oestrides. I. Revue Zoologique Africaine, 4: 144-161.

Papavero, N. 1977. The world Oestridae (Diptera), mammals and continental drift. Dr. W. Junk, The Hague. 240 pp.

Pont, A. C. 1980. 95. Family Oestridae, in Crosskey, R. W., ed. Catalogue of the Diptera of the Afrotropical Region. British Museum (Natural History), London. $1437 \mathrm{pp}$.

Rodhain, J., and Bequaert, J. 1915a. Sur quelques Oestrides du Congo (communication préliminaire). Bulletin de la Société de Pathologie Exotique, 8: 452-458.

1915b. Sur quelques Oestrides du Congo (2e communication préliminaire). Bulletin de la Société de Pathologie Exotique, 8: 687-695. .1915c. Sur quelques Oestrides du Congo (3e communication préliminaire). Bulletin de la Société de Pathologie Exotique, 8: 765-778.

1916. Matériaux pour une étude monographique des Diptères parasites de 1'Afrique. Deuxième partie. Révision des Oestrinae du continent africain. Bulletin scientifique de la France et de la Belgique, 7 (1-2): 53-164.

- 1920. Oestrides d'antilopes et de zèbres recueillis en Afrique orientale avec un conspectus du genre Gasterophilus. Revue Zoologique Africaine, 8: $169-228$ 
Sabrosky, C. W. 1986. North American species of Cuterebra, the rabbit and rodent bot flies (Diptera: Cuterebridae). Thomas Say Foundation Monographs, Volume 11, Entomological Society of America, College Park, Maryland. viii, 240 pp.

Zumpt, F. 1958. On Rhinoestrus steyni n. sp. and Gasterophilus zebrae Rodhain \& Bequaert (Diptera), parasites of Burchell's zebra (Equus burchelli Gray). Journal of the Entomological Society of Southern Africa, 21: 56-65.

. 1962. The oestroid flies of wild and domestic animals in the Ethiopian Region, with a discussion of their medical and veterinary importance (Diptera: Oestrinae \& Gasterophilidae). Zeitschrift für Angewandte Zoologie, 49: 393-419.

Zumpt, F., and Wetzel, H. 1970. Fly parasites (Diptera: Oestridae and Gasterophilidae) of the African elephant Loxodonta africana (Blumenbach) and their problems. Koedoe, 13: 109-121. 

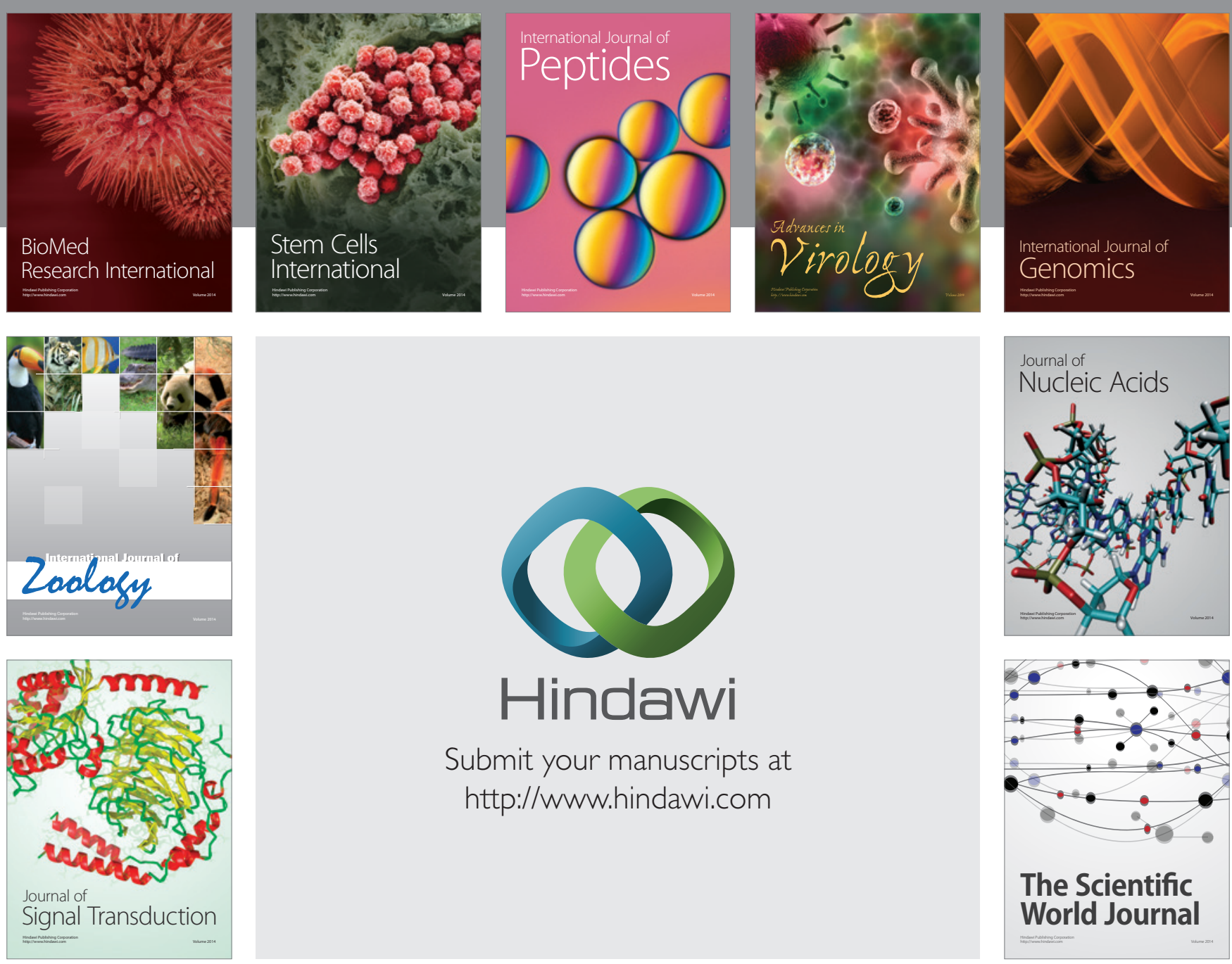

Submit your manuscripts at

http://www.hindawi.com
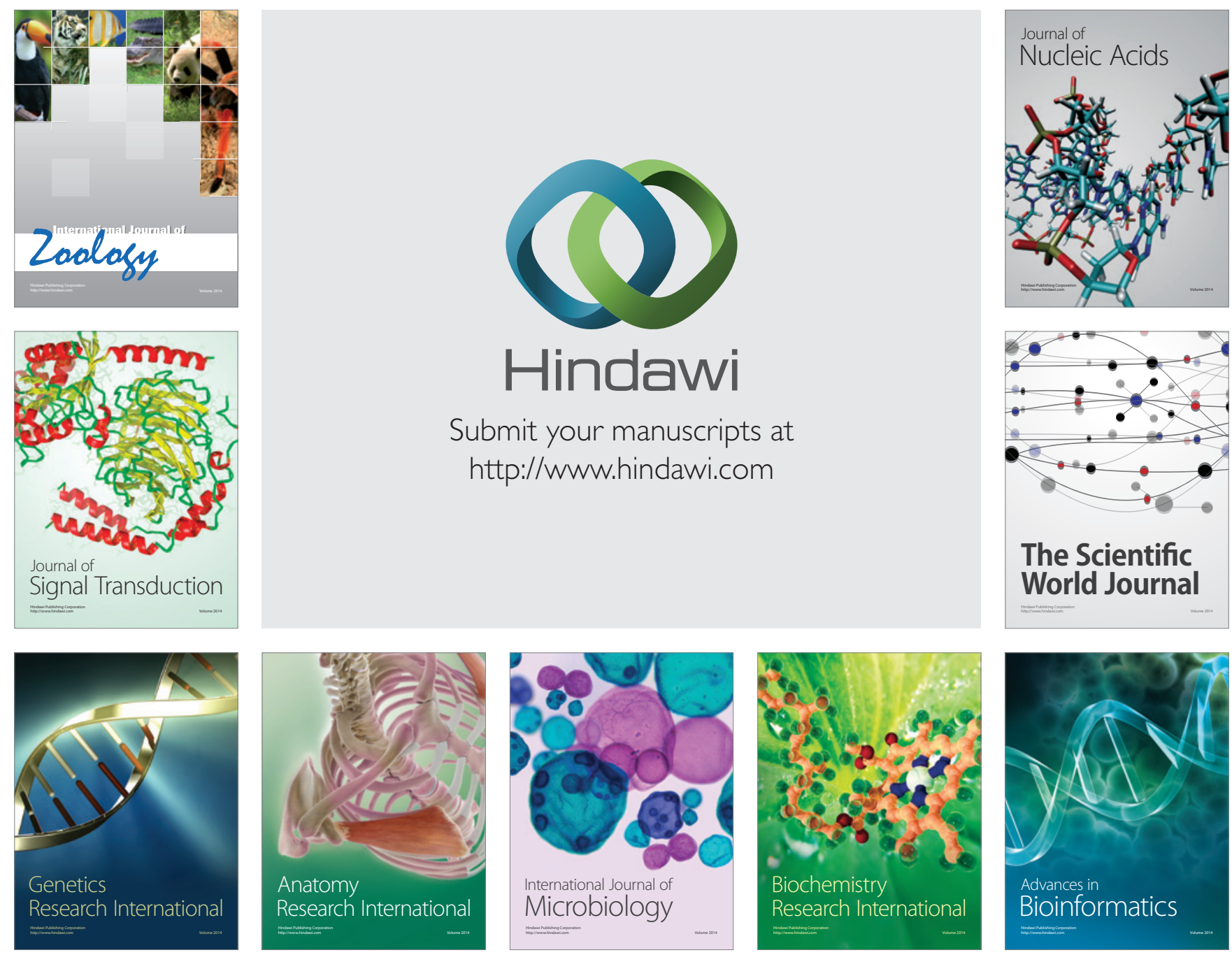

The Scientific World Journal
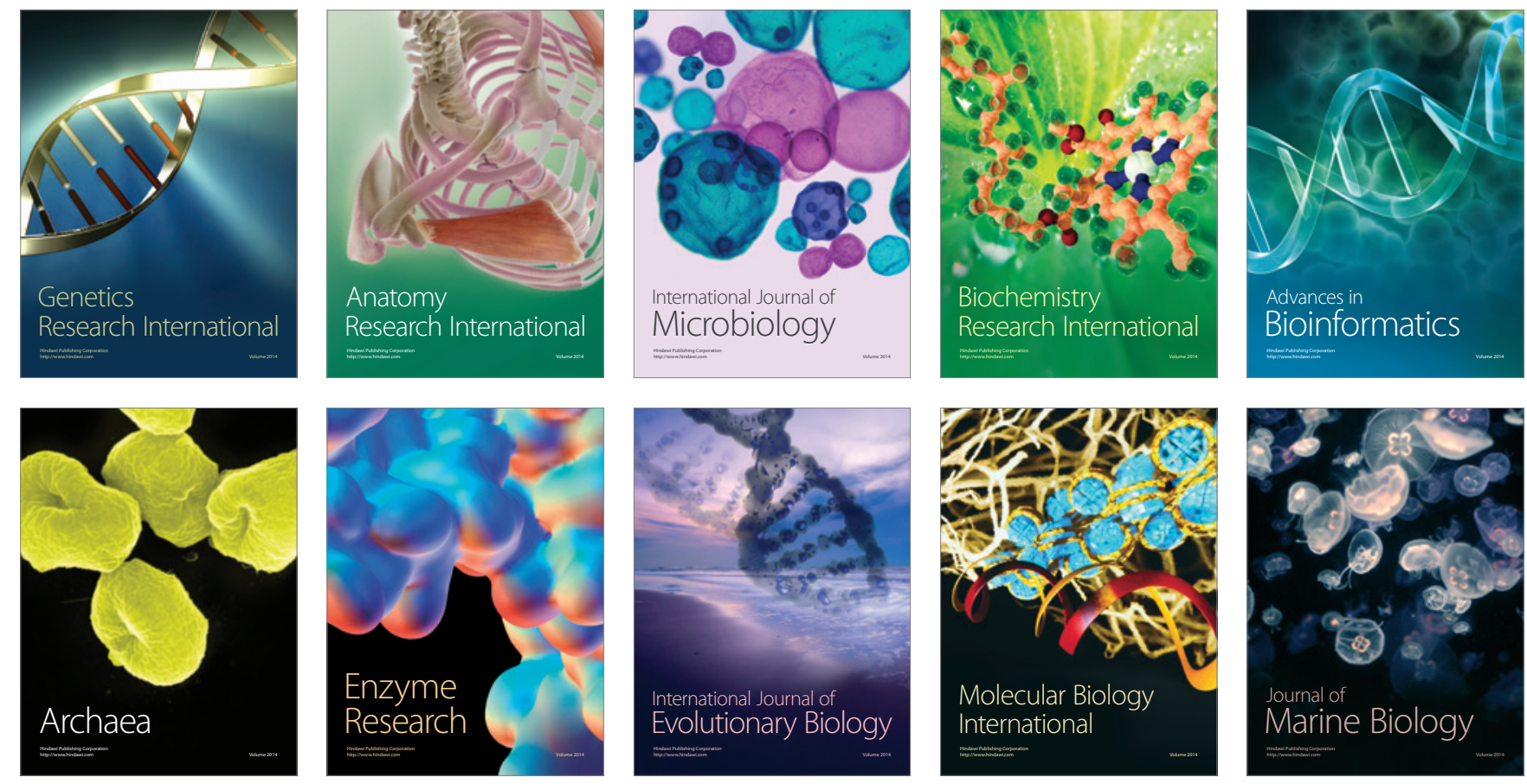